\title{
Genetic Balances that Maintain Potential Hypo-and Hyper- Activities in Physiological and Behavioral Characters
}

\author{
Dragoslav Marinkovic ${ }^{1} *$ and Suzana Cvjeticanin $^{2}$ \\ ${ }^{1}$ Serbian Academy of Sciences and Arts, Department of Chemical and Biological Sciences, 11000 \\ Belgrade, Serbia \\ ${ }^{2}$ Faculty of Medicine, Belgrade, R. Serbia
}

*Corresponding Author: Dragoslav Marinkovic, Serbian Academy of Sciences and Arts, Department of Chemical and Biological Sciences, 11000 Belgrade, Serbia.

\section{SHORT ORIGINAL RESEARCH REVIEW}

Individual variation is based on geneticphysiological balances that depend on allelic variants in polymorphic loci. Dominantrecessive relationships of these allelogenes establish also specific balances that vary in certain limits. The proportion of homozygouslyrecessive loci in an individual may have a normal variation, with extremes resulting in elite, deviant, or aberrant phenotypes.

During a 35-years study it has been realized that a number of clearly recessive morphophysiological traits may serve as an indicator of homozygosity of numerous genes that characterise a human individual. As phenotypic markers of these genes, we selected 20-30 recessive morpho-physiological traits in humans that may manifest the proportion of homozygosity of corresponding polymorphic genes that control observed characters (Marinkovic et al. 1990, 1994; Cvjeticanin and Marinkovic 2005a, b).

In an analysis of more than 20.000 inhabitans from different localities of R.Serbia, the HRCtest for the presence of homozygous-recessive characters has been applied. It was found that the average proportion of such characters varies moderately and within quite similar limits among inhabitants from one locality to the other, where studied populations were used as control-samples. However, when children from regular schools from a few places in Serbia were compared with HRC-test to those from special schools (e.g. with decreased hearing, visibility, or IQ-score, etc.), a significant increase of average homozygosity has been determined in second group. Almost such a difference, in the same direction, has been determined when adult 'healthy' individuals, as controls, were compared with samples of diseased persons, patients from different hospitals, such as those with congenital hip-luxation, balkan endemic nephropathy, urogenital, cardiovascular, diabetic, and some other diseases (Marinkovic and Cvjeticanin 2013), including, also, alcoholdependent people (Marinkovic et al. 2008). In all of mentioned samples, but a few (Basta et al. 1990), the average amount of HRCs was significantly higher than in control samples, with distribution curve clearly moved 'to the right'. In addition, a sample of high intelectuals, as well as a sample of left handed scholars, had a mild increase of such traits compared to a control sample of "street individuals".

Quite specific situation occurred when we proceeded an analysis of young individuals which are trained and selected to be sportsmen, such as good swimmers and future waterpolo players ( $\mathrm{PhD}$ thesis of S.Cvjeticanin 2001.). Out of hundreds of young school-boys that started in Belgrade to be trained for swimming achievements, less than one hundred succeeded to play in a few good waterpolo teams that compete at national and international level. In a sample of such young sportsmen, the average proportion of recessive morpho-physiological characters in our HRC-test was found to be about twice lower than in initial sample of school boys, suggesting a clear individual selection during the years of sharp training for this sport's achievement. Among thirty Serbian waterpolo representatives that were worldchampions (selected from hundreds of excellent players in best teams), the HRC-score was more than three times lower compared with a control sample of individuals (Cvjeticanin and Marinkovic 2009).

When a sample of male and female homosexuals were analyzed by HRC-test and compared to a control sample of heterosexuals, the similar direction of discrepancy as 
previously, i.e. a decrease of homozygous characters, was clearly determined (Marinkovic and Cvjeticanin 2013; Cvjeticanin 2015). This decrease amounted up to thirty percent, which, as well as a prevalent presence of 0-blood group, reminds to the balance observed previously in top-sportsmen. However, the combination of the characters that were homozygous in homosexuals vs. top-sportsmen was quite different, suggesting that two polygenic balances may have a different basis and developmental origin.

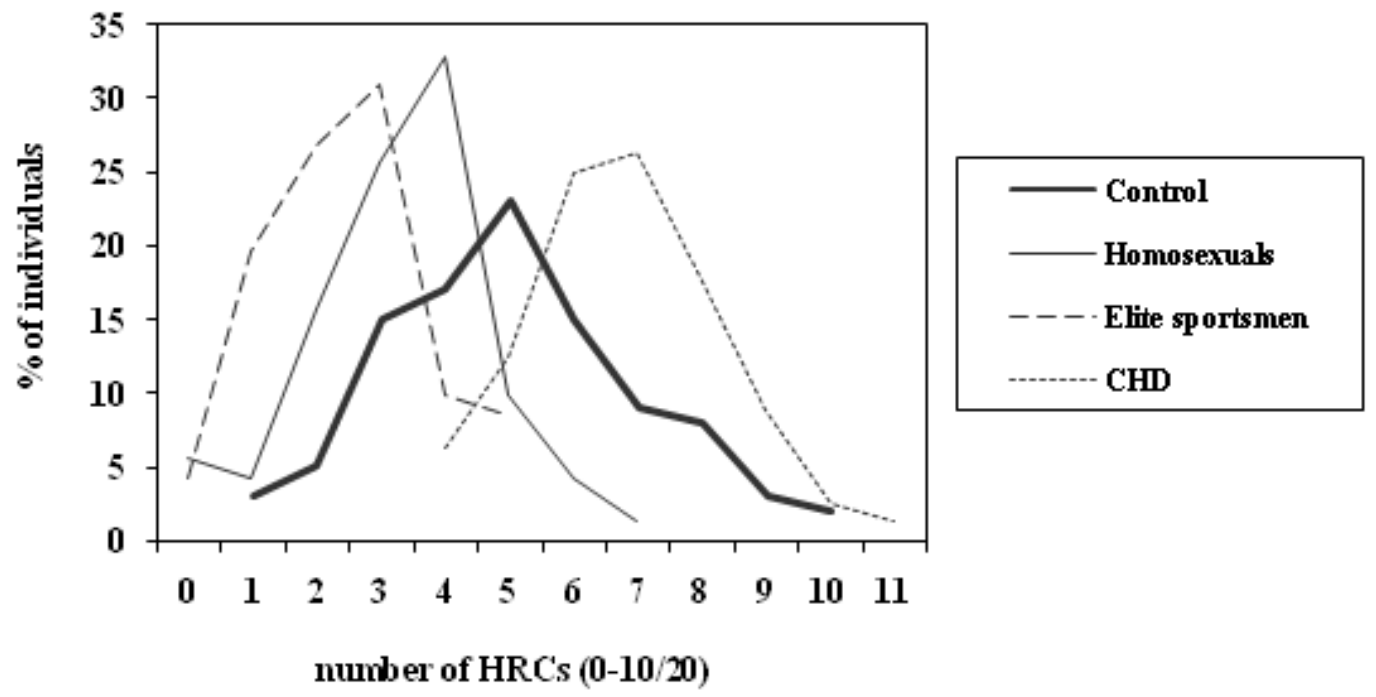

Figure1. Distribution of homozygously-recessive characteristics (HRC-test) based on the study of 20 qualitative morpho-physiological traits in the groups of elite sportsmen, homosexuals and control, compared with a sample of patiens with the congenital hip dislocation. (54. Congress of Anthropological Society of Serbia, Zlatibor 2018).

The results presented above (see, also, Figure 1) are positively suggesting that genetic balances based on a decrease of proportion of homozygous loci in human genotypes (with an observed change of genetic variability) may lead in a majority of cases to an increase of resistance to some diseases and to a potential physiological hyperactivity (e.g., Petronic et al. 2020). This may give also a predisposition for high sport-achievements, but in some other directions also to a homosexual behavior. We don't believe that these predispositions have a common root and growth origin, which should be explained in further analyses. It is most probable that not only proportion, but kind and amount of changes in genetic homozygosity contribute to a physiological balance that results in so called 'adaptive combinations' of fitness properties in humans.

\section{REFERENCES}

[1] Basta M., N. E. Morton, J. Mulvihill, Z. Radovanovic, C. Radojicic, D. Marinkovic, 1990. Inheritance of accute appendicitis: Familial aggregation and evidence of polygenic transmission. Am. J. Human Genetics 46: $377-$ 382.
[2] Cvjeticanin S. and Marinkovic D., 2005. Genetic variability in the group of patients with congenital hip dislocation. Rus. J. of Genetics 41 / 8, 936-940.

[3] Cvjeticanin S. and Marinkovic D., 2005. Genetic variability and frequencies of $\mathrm{ABO}$ blood types among different samples of patients from Serbia. Korean J. Genetics 27 (1), 35-40.

[4] Cvjeticanin S, Marinkovic D., 2009. Morphogenetic variability during selection of elite water polo players. J. Sports Sci. 2009; 27 (9) : 941-947.

[5] Cvjetićanin S., 215. Anthropogenetic variability in the groups of homo and heterosexually oriented individuals. Genetika, 2015, 47 (2) : 765-776

[6] Marinkovic D., Spremo B., Ilic M., 1990. Studies of human population-genetic variation. I. Comparisons of homozygously recessive traits in attendance of special and regular schools in SR Srbia. Arch. Biol. Sci. Belgrade, 42 (3-4), 11p-12p.

[7] Marinkovic D., D. Jovanovic, S. Cvjeticanin, M. Savic, S. Brankovic, 1994. Genetic homozygosity and normal vs. pathological human variation. Genetika 26 (3), 147-156.

[8] Marinkovic D., S. Cvjeticanin, M. Stanojevic, 2008. Population genetic analyses of 
Genetic Balances that Maintain Potential Hypo-and Hyper-Activities in Physiological and Behavioral Characters

susceptibility to developing alcohol dependence. Addiction Research and Theory, August 2008; 16 (4): 331-337.

[9] Marinkovic D. and S. Cvjeticanin, 2013. Anthropogenetic homozygosity and adaptive variability. Serbian Acad. Sci. and Arts, Monographs, book 172, pp. 1-215.
[10] Petronic I., D. Marinkovic, D. Nikolic, D. Cirovic, D. Golubovic, F. Milanovic, S. Cvjeticanin, 2020. Morphogenetic variability as potential biomarker of neurogenic lesion degree in children with Spina bifida. Healthcare 2020, 8, 68; doi:10.3390, pp. 1-9.

Citation: Dragoslav Marinkovic \& Suzana Cvjeticanin, "Genetic Balances that Maintain Potential Hypoand Hyper-Activities in Physiological and Behavioral Characters”, International Journal of Research Studies in Medical and Health Sciences. 2020; 5(8): 36-38.

Copyright: () 2020 Dragoslav Marinkovic \& Suzana Cvjeticanin, This is an open-access article distributed under the terms of the Creative Commons Attribution License, which permits unrestricted use, distribution, and reproduction in any medium, provided the original author and source are credited. 